\title{
Evaluation of Experimental Broccoli Hybrids Developed for Summer Production in the Eastern United States
}

\author{
Mark W. Farnham ${ }^{1,3}$ \\ U.S. Department of Agriculture, Agricultural Research Service, U.S. Vegetable \\ Laboratory, 2700 Savannah Highway, Charleston, SC 29414 \\ Thomas Björkman² \\ Department of Horticulture, NYSAES, Cornell University, Geneva, NY 14456
}

Additional index words. Brassica oleracea Italica Group, heat tolerance, environmental stress, vernalization

\begin{abstract}
Broccoli (Brassica oleracea L. Italica Group) is a vegetable crop requiring relatively cool conditions (e.g., less than $23^{\circ} \mathrm{C}$ ) to induce and maintain vernalization and to allow normal floral and head development to proceed. In general, this requirement is a major limiting factor to production of broccoli in eastern states where growing seasons are often interrupted by high temperature spikes. The USDA, ARS, U.S. Vegetable Laboratory (USVL) is conducting a program to breed broccoli varieties adapted to summer conditions of the southeastern United States. The goal of the current study was to compare performance of three experimental broccoli hybrids from that program with some commonly raised commercial hybrids ('Packman', 'Marathon', 'Arcadia', 'Greenbelt', 'Patron', and 'Gypsy') by conducting trials in summer environments as well as in more conventional growing environments (e.g., in fall). All hybrids produced marketable heads with high quality ratings in fall field trials $(2006,2007$, and 2008). Under the high temperatures that were characteristic of the summer $(2007,2008$, and 2009) trials in South Carolina, the commercial hybrids 'Marathon', 'Greenbelt', 'Arcadia', and 'Patron' failed to produce broccoli heads at all. The remaining hybrids produced heads with similar mean head mass, stem diameter, and bead size in South Carolina summer trials. However, the three experimental hybrids produced marketable quality heads, but 'Gypsy' and 'Packman' did not. The primary flaws in 'Gypsy' and 'Packman' heads were increased yellow color, flattening of the dome, increased roughness, and non-uniformity of bead size. In New York trials, all tested hybrids developed heads, but 'Packman' and 'Marathon' produced relatively poor-quality heads when maturing in summer and better quality heads when maturing in the fall. The experimental hybrids exhibited more consistent quality across different maturity times in the New York tests. Results of this research indicate that broccoli response to summer conditions of the eastern United States is dependent on the cultivar grown. Many cultivars are not adapted to extreme summer conditions of the Southeast because they will not be effectively vernalized and will therefore not head. Others such as 'Gypsy' and 'Packman' will head, but non-uniform bud development results in a rough-appearing curd in which flower buds are at various stages of development. The experimental hybrids that are single crosses of inbreds selected for adaptation to southeastern summer conditions represent a unique class of broccoli hybrids that combine early maturity and the ability to produce heads under summer conditions of South Carolina. Additional tests of these latter hybrids in New York indicate that they may be generally adapted to summer environments of the eastern United States.
\end{abstract}

Broccoli (Brassica oleracea L. Italica Group) has risen from the status of a very minor vegetable in the United States in the

Received for publication 10 Jan. 2011. Accepted for publication 14 Apr. 2011.

We acknowledge the excellent technical assistance of Mr. David Couillard and Mr. Joseph W. Shail, Jr., in conducting the field research components of this project.

${ }^{1}$ Research Geneticist.

${ }^{2}$ Associate Professor.

${ }^{3}$ To whom reprint requests should be addressed; e-mail Mark.Farnham@ars.usda.gov.
This renewed interest is coming at a time when fuel costs are making it very expensive to ship broccoli from the West.

Aside from the obvious limitation that broccoli cannot be grown during winter months in much of the East, an additional limitation to production during eastern summers is the likelihood of relatively hot temperatures that could reduce vegetable quality. Indeed, there is not an extended cool growing season in most eastern environments, and this tends to limit when and where current cultivars can be raised. In general, cool conditions are required both to induce and maintain vernalization and to allow normal floral development to proceed. If vernalization fails, no head is formed (Wurr et al., 1995). If the coordination of floral development is disrupted, the resulting uneven head is unmarketable (Björkman and Pearson, 1998). Broccoli normally has an extended meristem proliferation period to produce the complex inflorescence and then a second preanthesis arrest that allows for head enlargement without bolting or flowering.

Once floral development of broccoli is initiated, the process appears to be arrested by temperatures exceeding $30{ }^{\circ} \mathrm{C}$, temperatures that can be optimal for vegetative growth as long as they do not exceed 34 to $35^{\circ} \mathrm{C}$ (Björkman and Pearson, 1998). It is this sensitivity to warm temperatures near harvest, more than any other factor, that pushes U.S. broccoli production to climates with an extended cool growing season. Few studies have been conducted to examine variation among broccoli varieties in their development under high temperatures. Heather et al. (1992) evaluated a collection of broccoli hybrids for heat tolerance and holding ability in summer productions on Long Island, NY. Those authors identified certain hybrids that yielded more marketable heads and that held their head quality longer than others. They found that heat stress was most damaging $\approx 3$ weeks before harvest, at which time they calculated the immature inflorescence to be 5 to $10 \mathrm{~mm}$ in diameter. Björkman and Pearson (1998) studied temperature arrest in the broccoli hybrid 'Galaxy' and determined the critical sensitive stage was during floral initiation, which occurs when the shoot tip has a diameter less than $5 \mathrm{~mm}$ and the apical meristem is less than $2 \mathrm{~mm}$. Those authors found that the heat stress had little effect before or after that stage.

A greater number of studies have evaluated the effect of low temperatures on the initiation of inflorescence development (Fontes et al., 1967; Fontes and Ozbun, 1972; Gauss and Taylor, 1969) and premature bolting of the crop (Miller et al., 1985). These studies tend to disagree about whether broccoli exhibits a juvenile stage similar to other $B$. oleracea vegetables, which usually lasts until the six- to eight-leaf stage, during which time cold will not stimulate a shift from vegetative to reproductive growth (Warne, 1961). After this time, temperatures below $15{ }^{\circ} \mathrm{C}$ appear to be necessary to stimulate inflorescence development. Fontes et al. (1967) concluded that broccoli has a quantitative cold requirement for flowering. Wurr et al. 
(1995) developed a model for vernalization in broccoli and postulated an upper temperature limit for vernalization at $23.6^{\circ} \mathrm{C}$, above which plants are expected to remain vegetative.

In the early 1990 s, we initiated a program to breed broccoli varieties adapted to hot summer conditions of the southeastern United States. At the outset, all commercial broccoli hybrids available were evaluated in summer field trials in South Carolina and the best performing hybrids were identified (Dufault and Farnham, 1996). Those best performers were subsequently selfed to create inbreds and then crossbred to develop segregating populations in which to select for improved adaptation. Ultimately, only a few hybrids out of dozens examined initially contributed to the starting germplasm pool from which selections were made. Since making the original selections, this project has advanced through several cycles of recombination. Our selection environments are continuously hot with plants grown from transplant to maturity during conditions traditionally considered too hot for broccoli. Adaptation to the southeastern summer environment has been slowly increasing with each cycle of recombination (unpublished data).

The goal of the current study was to compare selected experimental hybrids that were developed for adaption to summer conditions with some commonly raised commercial broccoli hybrids for performance in field trials. Specifically, our objective was to evaluate performance in our high-temperatureselection environments (summer) as well as in more conventional growing environments occurring during fall in South Carolina, when a majority of broccoli hybrids will produce high-quality heads. An additional objective was to test whether selection under the severe conditions in South Carolina also confers adaptation to summer growing conditions in a northeastern environment.

\section{Materials and Methods}

Plant materials. Nine broccoli hybrids were grown in field trials described subsequently. Three experimental hybrids, designated USVL HY1, USVL HY4, and USVL HY5, were developed by the USVL breeding program for adaptation to summer conditions. All three of these hybrids are single crosses of conventional inbred lines; pedigrees of these are described in Table 1. All hybrid seed was generated by bud crosses in a winter greenhouse at Charleston, SC. Six additional commercial hybrids used in this research were 'Packman', obtained from Seminis Seed (currently Monsanto Vegetables, Saticoy, CA), and 'Arcadia', 'Greenbelt', 'Gypsy', 'Marathon', and 'Patron', all obtained from Sakata Seed Inc. (Morgan Hill, CA). The commercial hybrids chosen as checks were not selected as a result of their specific response to high temperatures; they were picked because they are common varieties that have various maturities and horticultural phenotypes. 'Packman' is considered

Table 1. Pedigrees of the inbred lines combined to make the experimental single cross hybrids USVL HY1, USVL HY4, and USVL HY5 evaluated in the summer (2006, 2007, and 2008) and fall (2007, 2008, and 2009) field trials described here.

\begin{tabular}{|c|c|c|c|}
\hline Single cross hybrid & Parent & Line designation & Pedigree \\
\hline \multirow[t]{2}{*}{ USVL HY1 } & Female & USVL110 & $\begin{array}{l}\text { F }_{9} \text {-derived selection from the hybrid } \\
\text { 'Green Comet' }\end{array}$ \\
\hline & Male & USVL112 & $\begin{array}{l}\mathrm{S}_{5} \text {-derived selection from the inbred population } \\
\text { 'NY1142' obtained from M. Dickson }\end{array}$ \\
\hline \multirow[t]{2}{*}{ USVL HY4 } & Female & USVL118 & $\begin{array}{l}\mathrm{F}_{6} \text {-derived selection from a segregating population } \\
\text { formed by crossing an } \mathrm{F}_{5} \text {-derived line from } \\
\text { 'Green Comet' and an } \mathrm{F}_{5} \text {-derived line from the } \\
\text { hybrid 'Paragon' }\end{array}$ \\
\hline & Male & USVL112 & $\begin{array}{l}\mathrm{S}_{5} \text {-derived selection from the inbred population } \\
\text { 'NY1142' obtained from M. Dickson }\end{array}$ \\
\hline \multirow[t]{2}{*}{ USVL HY5 } & Female & USVL109 & $\begin{array}{l}\mathrm{F}_{6} \text {-derived selection from a segregating population } \\
\text { formed by crossing an } \mathrm{F}_{5} \text {-derived line from } \\
\text { 'Green Comet' and an } \mathrm{F}_{5} \text {-derived line from the } \\
\text { hybrid 'Paragon' }\end{array}$ \\
\hline & Male & USVL114 & $\begin{array}{l}\mathrm{F}_{8} \text {-derived selection from a segregating population } \\
\text { formed by crossing an } \mathrm{F}_{5} \text {-derived line from } \\
\text { 'Green Comet' and an } \mathrm{F}_{6} \text {-derived line from the } \\
\text { hybrid population NY } 4506 \times \mathrm{NY} 6702 \text { obtained } \\
\text { from M. Dickson }\end{array}$ \\
\hline
\end{tabular}

an Eastern standard and 'Marathon' a Western standard.

Field trials. At the USVL in South Carolina, hybrids were grown in three fall trials in 2006, 2007, and 2008 and in three summer trials in 2007, 2008, and 2009. Eight of the hybrids were grown in all six South Carolina trials; 'Packman' was grown in all of those trials except the first fall (2006) and first summer (2007) trial. Fall trials were seeded the second week of August into a commercial potting mix (Fafard 3B; Conrad Fafard Inc., Agawam, MA) in 200-cell seedling trays (Speedling Inc., Sun City, FL) and kept in a greenhouse receiving no supplemental light with temperatures ranging from 25 to $32{ }^{\circ} \mathrm{C}$. Summer trials were seeded the same as described previously during the third week of April. Transplants were set in the field for the fall field trials on 15 Sept. 2006, 17 Sept. 2007, and 17 Sept. 2008 and for the summer trials on 25 May 2007, 28 May 2008, and 31 May 2009. In general, seedlings were 4 to 5 weeks old at transplanting.

All field trials were conducted using identical designs. The experimental design was a randomized complete block design with three replications. Each plot was planted with 20 plants of a given entry. A single row of plants was grown on raised beds with spacing between rows set at $102 \mathrm{~cm}$ and spacing between plants within a row at $15 \mathrm{~cm}$. All cultural practices were standard for local conditions and have been described previously (Farnham et al., 2000). In all of the trials described here, plants were watered as needed using a drip irrigation system. In addition, plots were side-dressed with 300 $\mathrm{kg} \cdot \mathrm{ha}^{-1}$ calcium nitrate at $\approx 3$ and 6 weeks after transplanting. The soil type for the Charleston trials was a Yonges loamy fine sand.

As plots approached maturity, they were observed every 2 to $3 \mathrm{~d}$, and those heads that had reached 10 to $12 \mathrm{~cm}$ in diameter were evaluated for quality traits. Three heads per plot were sampled at random, and subtending stalks were cut to a $16-\mathrm{cm}$ length. These sample heads were weighed and stem diameter of the cut stem was measured with a caliper. Sample dates were recorded for calculation of the mean number of days from transplant to harvest (DTH) on a plot basis. In addition to this sampling, horticultural traits (i.e., head color, shape, smoothness, firmness, bead size, bead uniformity, and overall quality) were assessed and recorded on a total of six plants per plot. Bead size was also measured with a caliper; all other traits were scored as a rating from 1 to 5 with 1 being the best score and 5 the worst for a given trait. Rating scores were as follows: 1 ) for head color $1=$ deep green to blue green, 2 = blue green, $3=$ blue green to light green, $4=$ lime, and $5=$ yellow; 2) for head shape $1=$ high dome, $2=$ medium dome, $3=$ low dome, $4=$ flat, and $5=$ concave; 3 ) for head smoothness $1=$ perfectly smooth bead surface, $2=$ smooth, but not perfect, $3=$ some irregularity, $4=$ very bumpy surface, and $5=$ very distorted surface; and 4) for bead uniformity $1=$ all beads perfectly uniform, 2 = uniform, but not perfectly, $3=$ some lack of uniformity, $4=$ irregular uniformity, and $5=$ highly irregular. The overall quality rating took into account all of these quality traits and is a subjective score from 1 to 9 with 1 = highest quality head, 2 = excellent quality, $3=$ very good head quality $4=$ good quality, $5=$ acceptable quality, marketable, $6=$ poor quality, nonmarketable, $7=$ very poor quality, $8=$ nearly unrecognizable as broccoli, and $9=$ not recognizable as broccoli (e.g., more cauliflowerlike). Individual plant measurements or ratings were averaged to compute a plot mean for each trait.

New York trials were performed similarly and conducted at the Cornell University State Agricultural Experiment Station Vegetable Research Farm in Geneva. Seed of 'Marathon' (Western standard), 'Packman' (Eastern standard), USVL HY1, and USVL HY4 (2007 and 2008 only) were sown into 50-cell polyethylene flats filled with Cornell Mix A (Boodley and Sheldrake, 1977) and raised in a greenhouse set to $15{ }^{\circ} \mathrm{C}$ night, $20^{\circ} \mathrm{C}$ day for 
4 weeks. They were then hardened in cold frames for 1 week before setting in the field. The transplanting dates for the New York trials were 1 June, 15 June, 1 July, and 15 July in 2006, 2007, and 2008. Generally, 1 June plantings at this site are most likely to experience injurious, high-temperature conditions, whereas 15 July transplanting generally results in excellent maturation in cool fall weather. Soil type used for these trials was a Honeoye Silt Loam, a highly productive alfisol.

Plants were set in the field in a single row at $30-\mathrm{cm}$ spacing on beds separated by $2 \mathrm{~m}$ and covered by plastic mulch and set with tape for drip irrigation and liquid fertilizer injection. Each entry was set in four replications of five plants each. Performance was scored at maturity for several traits on each plant. Two that correspond to the South Carolina site were the focus of the study and are reported here: days to maturity and bead uniformity. Bead uniformity was the trait that varied most consistently across New York trials and is the one quality criterion that broccoli most often fails to meet in summer trials in New York State.

Statistical analysis. For the South Carolina trials, results from each individual environment were first analyzed as separate experiments to examine entry effects on all traits. Data from the three fall trials were combined to examine hybrid and hybrid-by-year interactions, and data from the three summer trials were similarly analyzed. Analysis of variance was performed using Proc GLM of SAS (Release 9.1; SAS Institute, Inc., Cary, NC). Mean separation was conducted using a protected least significant difference. Because individual hybrids had drastically different responses when compared for performance in fall versus summer, all data (e.g., from all six trials) for a given hybrid were combined and analyzed separately to determine if significantly different responses to season were evident using single degree of freedom contrasts in analysis of variance. Hybrid and season were treated as fixed effects and year was treated as a random effect.

\section{Results and Discussion}

The optimal season for broccoli production in the southeastern United States has generally been considered to be the fall with direct seeding or transplanting being accomplished in late summer to early fall and the crop maturing in the relatively dry and cool period of the year from November through December. In this study, fall production in South Carolina served as a control environment wherein production is considered to be optimal for this region. The average high and low temperatures during the fall season from 2006 through 2008 were typical (Fig. 1). At the start of the season, daily highs generally ranged between 25 and $30{ }^{\circ} \mathrm{C}$, whereas lows were near $20{ }^{\circ} \mathrm{C}$. By late in the growing season, high temperatures fluctuated significantly between 15 and $25^{\circ} \mathrm{C}$, whereas lows were mostly between 5 and $10^{\circ} \mathrm{C}$.
Analysis of variance of all data from South Carolina fall trials indicated that significant $(P<0.05)$ differences among years were observed for nearly all traits examined; however, genotype-by-year interactions for most traits were not significant (data not shown). This indicated that although trait means varied among the test years, the ranking of genotypes (hybrids) did not. Thus, hybrid means are presented averaged across the 3 years (Table 2).

All of the tested hybrids performed well in the fall trials. The experimental USVL hybrids matured earlier than the other hybrids, all within 60 DTH (Table 2). 'Packman' was also relatively early with 61.0 DTH. The other hybrids were later with 'Marathon' exhibiting the longest mean DTH of $86.6 \mathrm{~d}$. The later maturing hybrids produced heads that had mean fresh weight greater than $200 \mathrm{~g}$ and mean stem diameter greater than $30 \mathrm{~mm}$, whereas the early-maturing experimental hybrids and 'Packman' had mean head mass under $200 \mathrm{~g}$ and stem diameter less than 30 mm (Table 2). USVL HY5 had the largest head mass and stem diameter of the three

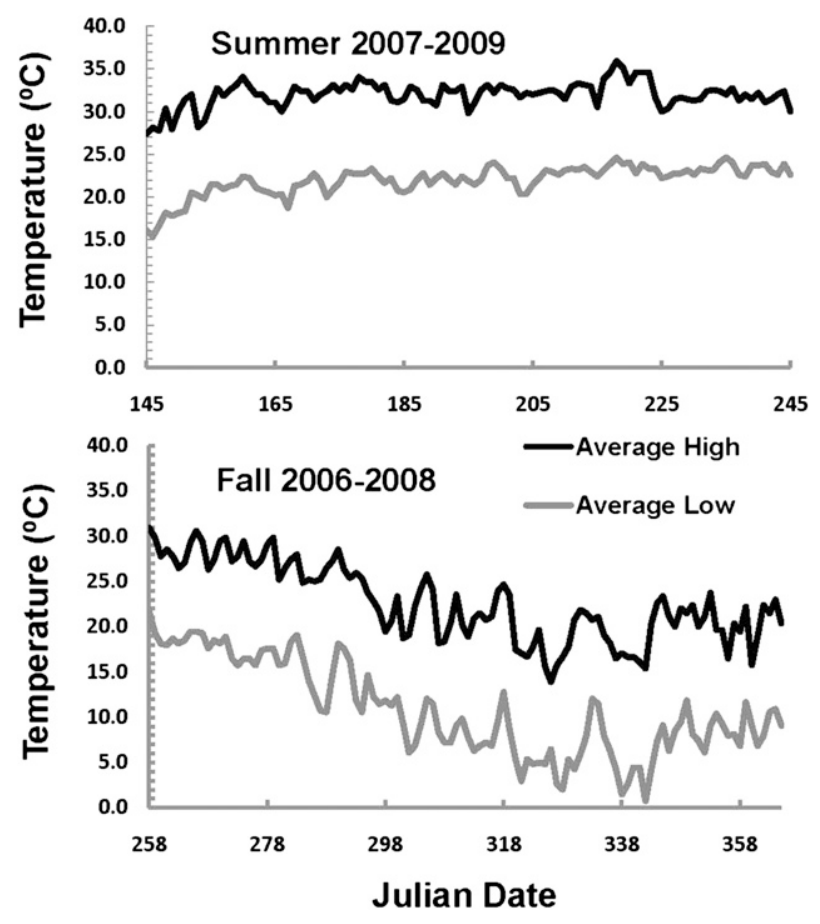

Fig. 1. Average high and low temperatures during three summer (2007, 2008, and 2009) trials (top) and during three fall $(2006,2007$, and 2008) trials (bottom) conducted at Charleston, SC.

Table 2. Trait means for days from transplant to harvest (DTH), head mass, stem diameter, bead size and color, shape, smoothness (smooth), and overall quality (Q) ratings for nine broccoli hybrids grown in three fall environments in Charleston, SC, in 2006, 2007, and 2008.

\begin{tabular}{llllllllll}
\hline & $\begin{array}{c}\text { DTH } \\
\text { (days) }\end{array}$ & $\begin{array}{c}\text { Color }^{\mathrm{y}} \\
\text { rating }\end{array}$ & $\begin{array}{c}\text { Shape }^{\mathrm{x}} \\
\text { rating }\end{array}$ & $\begin{array}{c}\text { Smooth }^{\mathrm{w}} \\
\text { rating }\end{array}$ & $\begin{array}{c}\text { Overall } \\
\mathrm{Q}^{\mathrm{v}} \\
\text { rating }\end{array}$ & $\begin{array}{c}\text { Bead } \\
\text { size } \\
(\mathrm{mm})\end{array}$ & $\begin{array}{c}\text { Bead } \\
\text { uniformity } \\
\text { rating }\end{array}$ & $\begin{array}{c}\text { Head } \\
\text { mass } \\
(\mathrm{g})\end{array}$ & $\begin{array}{c}\text { Stem } \\
\text { diam } \\
(\mathrm{mm})\end{array}$ \\
\hline Marathon & $86.6 \mathrm{a}$ & 2.2 & $1.8 \mathrm{e}$ & $2.0 \mathrm{c}$ & $3.7 \mathrm{e}$ & $1.48 \mathrm{~d}$ & $1.8 \mathrm{e}$ & $250.0 \mathrm{a}$ & $34.5 \mathrm{a}$ \\
Greenbelt & $83.6 \mathrm{~b}$ & 2.2 & $2.0 \mathrm{bcde}$ & $2.3 \mathrm{a}$ & $4.0 \mathrm{~cd}$ & $1.52 \mathrm{~d}$ & $2.0 \mathrm{cde}$ & $219.3 \mathrm{bc}$ & $33.7 \mathrm{ab}$ \\
Arcadia & $80.7 \mathrm{c}$ & 2.2 & $2.1 \mathrm{bc}$ & $2.3 \mathrm{a}$ & $4.4 \mathrm{bc}$ & $1.60 \mathrm{c}$ & $2.2 \mathrm{a}$ & $200.2 \mathrm{~cd}$ & $30.5 \mathrm{c}$ \\
Patron & $78.9 \mathrm{c}$ & 2.3 & $2.1 \mathrm{bc}$ & $2.3 \mathrm{a}$ & $3.8 \mathrm{de}$ & $1.34 \mathrm{e}$ & $2.0 \mathrm{cde}$ & $233.9 \mathrm{ab}$ & $33.8 \mathrm{ab}$ \\
Gypsy & $74.6 \mathrm{~d}$ & 2.6 & $1.9 \mathrm{cde}$ & $2.0 \mathrm{c}$ & $3.6 \mathrm{e}$ & $1.56 \mathrm{~cd}$ & $1.9 \mathrm{de}$ & $236.5 \mathrm{ab}$ & $31.5 \mathrm{bc}$ \\
Packman & $61.0 \mathrm{e}$ & 2.3 & $2.8 \mathrm{a}$ & $2.2 \mathrm{ab}$ & $4.9 \mathrm{a}$ & $1.92 \mathrm{a}$ & $2.2 \mathrm{ab}$ & $177.8 \mathrm{de}$ & $29.4 \mathrm{c}$ \\
USVL HY1 & $59.9 \mathrm{e}$ & 2.5 & $2.1 \mathrm{bc}$ & $2.0 \mathrm{c}$ & $4.4 \mathrm{bc}$ & $1.83 \mathrm{~b}$ & $2.0 \mathrm{cde}$ & $165.0 \mathrm{e}$ & $29.4 \mathrm{c}$ \\
USVL HY4 & $59.7 \mathrm{e}$ & 2.6 & $1.9 \mathrm{de}$ & $2.0 \mathrm{c}$ & $4.2 \mathrm{bc}$ & $1.82 \mathrm{~b}$ & $2.0 \mathrm{cde}$ & $167.4 \mathrm{e}$ & $29.5 \mathrm{c}$ \\
USVL HY5 & $58.4 \mathrm{e}$ & 2.5 & $2.1 \mathrm{bcd}$ & $2.1 \mathrm{bc}$ & $4.5 \mathrm{~b}$ & $1.82 \mathrm{~b}$ & $2.1 \mathrm{abc}$ & $171.2 \mathrm{e}$ & $31.8 \mathrm{bc}$
\end{tabular}

zTrait means followed by same letter are not significantly $(P<0.05)$ different from one another based on analysis of variance and protected least significant difference.

${ }^{\mathrm{y}} \mathrm{Head}$ color is rated 1 to 5 with $1=$ deep green, $2=$ blue-green, $3=$ light green, $4=$ lime, and $5=$ yellow ${ }^{x}$ Head shape is rated 1 to 5 with $1=$ high dome, $2=$ medium dome, $3=$ low dome, $4=$ flat, and $5=$ concave.

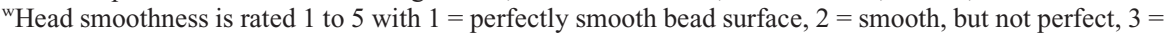
some irregularity, $4=$ very bumpy surface, and $5=$ very distorted surface.

vHead quality is rated 1 to 9 with 1 = highest quality head, $2=$ excellent quality, $3=$ very good head quality 4 = good quality, 5 = acceptable quality, marketable, $6=$ poor quality, nonmarketable, $7=$ very poor quality, $8=$ nearly unrecognizable as broccoli, and $9=$ not recognizable as broccoli (e.g., more cauliflowerlike).

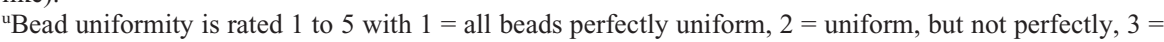
some lack of uniformity, $4=$ irregular uniformity, and $5=$ highly irregular. 
experimental hybrids. Bead size was greater in 'Packman' and the USVL hybrids than it was in the later maturing commercial hybrids (Table 2). The overall quality of heads produced in the fall was very good for all hybrids tested with the mean overall quality rating ranging from a best of 3.6 for 'Gypsy' to the worst of 4.9 for 'Packman', making all heads marketable. Although head quality traits, including color, shape, smoothness, and bead uniformity, varied significantly among hybrids grown in the fall in South Carolina, all mean rating scores were indicative of goodquality heads.

All three summer trials (2007 to 2009) were conducted in temperature regimes typical for South Carolina at that time of year (Fig. 1). From mid-June until the trials were ended in August, daily high temperatures were usually $30{ }^{\circ} \mathrm{C}$ or higher and average low temperatures seldom went lower than 20 to $23{ }^{\circ} \mathrm{C}$. Thus, except for the first 3 weeks of the summer trials, temperature conditions that prevailed during these tests are deemed too hot for commercial broccoli production with the quality of heads from commercial hybrids expected to be poor.

Under the high temperatures that were characteristic of the South Carolina summer trials, 'Marathon', 'Greenbelt', 'Arcadia', and 'Patron' failed to produce broccoli heads (Table 3). All of these hybrids remained vegetative throughout the duration of the summer. When trials were ended in August, abundant axillary shoot growth precluded formation of harvestable florets (Fig. 2). After 90 to $100 \mathrm{~d}$ in the field, these four commercial hybrids became a mass of lateral growth and they lacked a distinguishable central stem that would normally produce a large primary head.

The remaining five hybrids produced heads with similar mean head mass, stem diameter, and bead size in summer trials; however, the quality of heads was very different among these hybrids (Table 3). In general, the three USVL hybrids produced marketable quality heads, whereas 'Gypsy'
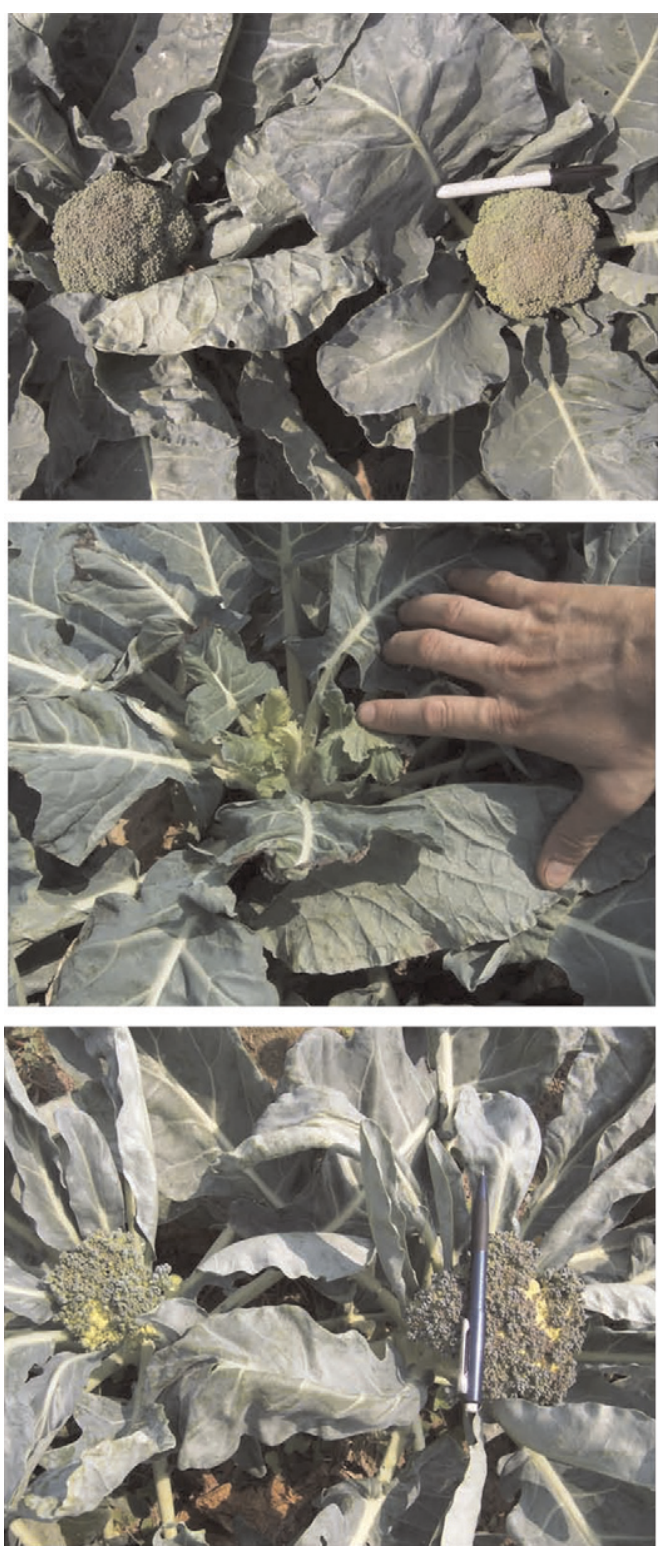

Fig. 2. Photographs show head production (or lack of) for different broccoli hybrids under hot summer conditions of the Charleston summer trials. All pictures were taken in July when plots matured. Top is USVL HY4, middle is 'Arcadia', and bottom shows 'Gypsy'.

Table 3. Trait means for days from transplant to harvest (DTH), head mass, stem diameter, bead size and color, shape, smoothness (smooth), and overall quality (Q) ratings for nine broccoli hybrids grown in three summer environments in Charleston, SC, in 2007,2008 , and 2009.

\begin{tabular}{|c|c|c|c|c|c|c|c|c|c|}
\hline Hybrid & $\mathrm{DTH}^{\mathrm{z}}$ (days) & Color $^{\mathrm{y}}$ rating & Shape $^{x}$ rating & Smooth $^{\mathrm{w}}$ rating & $\begin{array}{l}\text { Overall } Q^{v} \\
\text { rating }\end{array}$ & $\begin{array}{l}\text { Bead size } \\
\quad(\mathrm{mm})\end{array}$ & $\begin{array}{l}\text { Bead uniformity } \\
\text { rating }\end{array}$ & $\begin{array}{c}\text { Head mass } \\
(\mathrm{g})\end{array}$ & $\begin{array}{l}\text { Stem diam } \\
\quad(\mathrm{mm})\end{array}$ \\
\hline Marathon & No heads & No heads & No heads & No heads & No heads & No heads & No heads & No heads & No heads \\
\hline Greenbelt & No heads & No heads & No heads & No heads & No heads & No heads & No heads & No heads & No heads \\
\hline Arcadia & No heads & No heads & No heads & No heads & No heads & No heads & No heads & No heads & No heads \\
\hline Patron & No heads & No heads & No heads & No heads & No heads & No heads & No heads & No heads & No heads \\
\hline Gypsy & $61.1 \mathrm{a}$ & $3.2 \mathrm{a}$ & $3.1 \mathrm{~b}$ & $3.4 \mathrm{a}$ & $6.9 \mathrm{a}$ & 1.52 & $3.3 \mathrm{a}$ & $176.7 \mathrm{a}$ & 29.3 \\
\hline Packman & $56.5 \mathrm{~b}$ & $2.4 \mathrm{~b}$ & $3.5 \mathrm{a}$ & $3.5 \mathrm{a}$ & $7.0 \mathrm{a}$ & 1.64 & $3.0 \mathrm{~b}$ & $154.2 \mathrm{~b}$ & 29.9 \\
\hline USVL HY1 & $55.8 \mathrm{bc}$ & $2.1 \mathrm{~b}$ & $2.7 \mathrm{c}$ & $2.7 \mathrm{c}$ & $5.3 \mathrm{~b}$ & 1.59 & $2.4 \mathrm{c}$ & $160.2 \mathrm{ab}$ & 27.8 \\
\hline USVL HY4 & $55.8 \mathrm{bc}$ & $2.3 \mathrm{~b}$ & $2.3 \mathrm{~d}$ & $2.3 \mathrm{~d}$ & $4.9 \mathrm{~b}$ & 1.78 & $2.2 \mathrm{c}$ & $155.4 \mathrm{~b}$ & 28.7 \\
\hline USVL HY5 & $52.6 \mathrm{c}$ & $2.3 \mathrm{~b}$ & $2.3 \mathrm{~d}$ & $2.3 \mathrm{~d}$ & $4.6 \mathrm{c}$ & 1.75 & $2.3 \mathrm{c}$ & $146.1 \mathrm{~b}$ & 28.2 \\
\hline
\end{tabular}

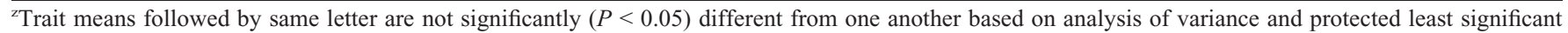
difference.

${ }^{\mathrm{y}}$ Head color is rated 1 to 5 with $1=$ deep green, $2=$ blue-green, $3=$ light green, $4=$ lime, and $5=$ yellow.

${ }^{x}$ Head shape is rated 1 to 5 with $1=$ high dome, $2=$ medium dome, $3=$ low dome, $4=$ flat, and $5=$ concave.

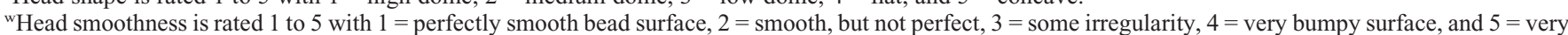
distorted surface.

${ }^{v}$ Head quality is rated 1 to 9 with $1=$ highest quality head, $2=$ excellent quality, $3=$ very good head quality $4=$ good quality, $5=$ acceptable quality, marketable, $6=$ poor quality, nonmarketable, $7=$ very poor quality, $8=$ nearly unrecognizable as broccoli, and $9=$ not recognizable as broccoli (e.g., more cauliflower-like). "Bead uniformity is rated 1 to 5 with $1=$ all beads perfectly uniform, $2=$ uniform, but not perfectly, $3=$ some lack of uniformity, $4=$ irregular uniformity, and $5=$ highly irregular. 
and 'Packman' did not. The primary flaws in 'Gypsy' and 'Packman' heads were increased yellow in head color, flattening of the dome, increased roughness, and more non-uniformity of bead size (Table 3; Fig. 2).

Comparing individual hybrid performance in fall versus summer revealed different trends among the hybrids that produced heads in both environments (Table 4). With 'Gypsy', mean values of all traits except bead size were significantly different in summer versus fall (Table 4). In all cases with 'Gypsy', heads matured significantly faster in summer than in fall, and head mass was smaller in summer. In addition, all traits associated with quality reflected significantly poorer quality in summer than fall. 'Packman' behaved similar to 'Gypsy', exhibiting poorer quality heads in summer versus fall. However, DTH, bead size, and head mass did not differ significantly for this hybrid between the very different seasonal environments. The overall poorer quality of 'Gypsy' and 'Packman' heads produced in summer made them unmarketable.

The experimental USVL hybrids (e.g., HY4 and HY5) that were developed for adaptation to the summer test environments performed similarly in each season (Table 4). USVL HY4 exhibited significantly better overall quality and bead uniformity in fall versus summer, but all other traits did not differ significantly, and heads grown in the summer remained marketable. USVL HY5 varied least in its performance between the two seasons. No significant differences between summer and fall trait means were observed for this hybrid. USVL HY1 performed similarly to USVL HY4, exhibiting some significant drops in quality in summer versus fall, but a majority of heads harvested from this variety had marketable characteristics in summer (Table 3; Fig. 2).

Results of the New York summer trials were different from results for the South Carolina trials. Regardless of the planting date in Geneva, all hybrids tested, including 'Marathon', formed heads (Fig. 3). In the Northeast, bead uniformity is the trait most often negatively impacted by high temperatures. With 'Marathon', the best quality heads were observed for the last transplanting date in all 3 years. This last date had 'Marathon' maturing in mid- to late September when temperatures were coolest. With earlier transplant dates, 'Marathon' exhibited poorer quality. When 'Packman' matured at the same time as 'Marathon', it almost always exhibited a better bead uniformity rating than 'Marathon' (Fig. 3). 'Packman' also tended

Table 4. Trait means for days from transplant to harvest (DTH), head mass, bead size and color, shape, smoothness (smooth), and overall quality (Q), and bead uniformity ratings of four broccoli hybrids grown in Charleston, $\mathrm{SC}$, in three summer and three fall environments.

\begin{tabular}{|c|c|c|c|c|c|c|c|c|c|}
\hline Hybrid & Environment & $\begin{array}{l}\text { DTH }^{z} \\
\text { (days) }\end{array}$ & $\begin{array}{l}\text { Color }{ }^{\mathrm{y}} \\
\text { rating }\end{array}$ & $\begin{array}{l}\text { Shape }^{\mathrm{x}} \\
\text { rating }\end{array}$ & $\begin{array}{l}\text { Smooth }^{\mathrm{w}} \\
\text { rating }\end{array}$ & $\begin{array}{c}\text { Overall } \\
Q^{v} \text { rating }\end{array}$ & $\begin{array}{l}\text { Bead } \\
\text { size } \\
(\mathrm{mm})\end{array}$ & $\begin{array}{l}\text { Bead } \\
\text { uniformity } \\
\text { rating }\end{array}$ & $\begin{array}{c}\text { Head } \\
\text { mass }(\mathrm{g})\end{array}$ \\
\hline \multirow{6}{*}{ Gypsy } & FA 2006 & $66.0 *$ & $2.4^{*}$ & $1.7^{* *}$ & $2.0 * *$ & $3.6^{* *}$ & 1.35 & $1.9^{* *}$ & $264.0 * *$ \\
\hline & FA 2007 & $75.3^{*}$ & $2.0 *$ & $2.0 * *$ & $2.0 * *$ & $3.4 * *$ & 1.70 & $1.8 * *$ & $239.6 * *$ \\
\hline & FA 2008 & $82.3^{*}$ & $2.0 *$ & $2.0 * *$ & $2.0 * *$ & $3.8 * *$ & 1.65 & $1.9 * *$ & $205.9 * *$ \\
\hline & SU 2007 & 60.3 & 3.4 & 3.4 & 3.3 & 6.8 & 1.59 & 3.6 & 175.1 \\
\hline & $S U 2008$ & 63.7 & 3.6 & 3.1 & 3.7 & 7.5 & 1.26 & 3.5 & 185.8 \\
\hline & SU 2009 & 59.3 & 2.7 & 2.7 & 3.4 & 6.4 & 1.70 & 2.8 & 169.2 \\
\hline \multirow[t]{4}{*}{ Packman } & FA 2007 & 62.0 & 2.0 & $2.8^{*}$ & $2.3 * *$ & $4.9 * *$ & 1.95 & $2.2 * *$ & 211.3 \\
\hline & FA 2008 & 60.0 & 2.0 & $2.8^{*}$ & $2.1 * *$ & $4.8 * *$ & 1.90 & $2.1 * *$ & 144.4 \\
\hline & $S U 2008$ & 59.0 & 2.5 & 3.6 & 3.5 & 6.7 & 1.77 & 3.0 & 151.3 \\
\hline & SU 2009 & 54.0 & 2.3 & 3.4 & 3.4 & 7.2 & 1.51 & 2.9 & 157.2 \\
\hline \multirow[t]{6}{*}{ USVL HY4 } & FA 2006 & 57.3 & 2.0 & 1.8 & 2.0 & $4.6^{*}$ & 1.70 & $2.0 *$ & 191.4 \\
\hline & FA 2007 & 56.0 & 2.0 & 2.2 & 2.1 & $4.3^{*}$ & 1.98 & $1.9^{*}$ & 181.2 \\
\hline & FA 2008 & 62.0 & 1.9 & 1.7 & 2.0 & $4.4^{*}$ & 1.76 & $2.0 *$ & 129.6 \\
\hline & $S U 2007$ & 55.7 & 2.6 & 2.7 & 2.4 & 5.0 & 1.83 & 2.2 & 147.1 \\
\hline & $S U 2008$ & 56.3 & 2.4 & 2.2 & 2.3 & 5.2 & 1.72 & 2.3 & 169.7 \\
\hline & SU 2009 & 55.3 & 2.0 & 2.0 & 2.0 & 4.7 & 1.80 & 2.2 & 149.3 \\
\hline \multirow[t]{6}{*}{ USVL HY5 } & FA 2006 & 58.0 & 2.1 & 2.1 & 2.1 & 4.4 & 1.75 & 2.0 & 167.4 \\
\hline & FA 2007 & 63.0 & 1.9 & 2.0 & 2.2 & 4.5 & 1.85 & 2.2 & 205.8 \\
\hline & FA 2008 & 58.0 & 2.1 & 2.1 & 2.1 & 4.5 & 1.86 & 2.0 & 140.3 \\
\hline & SU 2007 & 55.3 & 2.5 & 2.4 & 2.3 & 4.9 & 1.82 & 2.2 & 140.5 \\
\hline & $S U 2008$ & 55.3 & 2.1 & 1.9 & 2.1 & 4.3 & 1.70 & 2.4 & 145.7 \\
\hline & SU 2009 & 47.0 & 2.4 & 2.4 & 2.6 & 4.5 & 1.74 & 2.4 & 152.0 \\
\hline
\end{tabular}

z* and ** by fall trait means indicates a significant $(P<0.05$ or $P<0.01$, respectively) difference between the fall and summer trait means based on analysis of variance and single degree of freedom contrasts for a given trait and hybrid.

${ }^{y}$ Head color is rated 1 to 5 with $1=$ deep green, $2=$ blue-green, $3=$ light green, $4=$ lime, and $5=$ yellow ${ }^{\mathrm{x}}$ Head shape is rated 1 to 5 with $1=$ high dome, $2=$ medium dome, $3=$ low dome, $4=$ flat, and $5=$ concave.

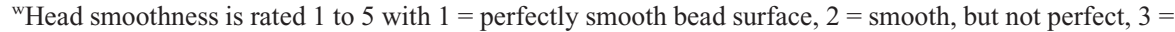
some irregularity, $4=$ very bumpy surface, and $5=$ very distorted surface.

"Head quality is rated 1 to 9 with 1 = highest quality head, $2=$ excellent quality, $3=$ very good head quality 4 = good quality, 5 = acceptable quality, marketable, $6=$ poor quality, nonmarketable, $7=$ very poor quality, $8=$ nearly unrecognizable as broccoli, and $9=$ not recognizable as broccoli (e.g., more cauliflowerlike).

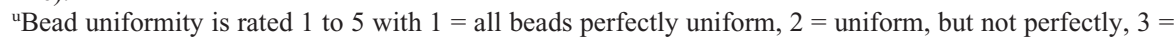
some lack of uniformity, 4 = irregular uniformity, and $5=$ highly irregular.

to exhibit the highest quality for the last transplant date, whereas heads harvested at the earlier dates had more flaws. USVL HY1 always exhibited better bead uniformity than 'Packman' or 'Marathon' and varied less for this trait across all transplant dates (Fig. 3). It was the least affected by variable conditions that occurred across transplant dates. USVL HY4, which was only tested in 2007 and 2008, performed very similar to USVL HY1 in 2008 but exhibited poorer quality (e.g., rating greater than 3 with the earliest transplant date; Fig. 3). Aside from this exception, these results confirmed that some commonly grown broccoli hybrids responded to warmer temperature regimes by yielding poorer quality heads, whereas the experimental USVL hybrids produced heads of similar quality regardless of the season in which they were grown. Apparently, selection of broccoli under the more severe heat conditions of southeastern summers has increased adaptation of
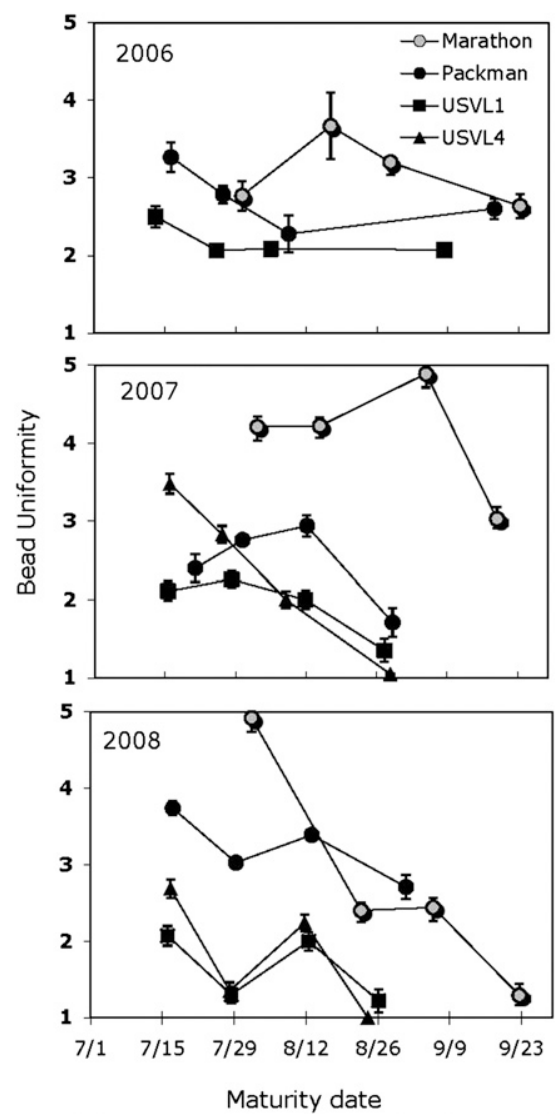

Fig. 3. Average bead uniformity rating and maturity for 'Marathon', 'Packman', USVL HY1, and USVL HY4 grown in Geneva, NY, from 2006 to 2008 and planted on four different dates (1 and 15 June and 1 and 15 July). In New York, injurious heat was episodic. Because it affects heads near maturity, the scores are plotted by harvest date to better align the scores with the stress. The bead uniformity scale was the same as used in South Carolina with $1=$ all beads perfectly uniform; 2 = uniform, but not perfectly, generally marketable; 3 = some lack of uniformity, limited marketability; 4 = irregular uniformity, generally unmarketable; and $5=$ highly irregular, unmarketable. Error bars indicated the SE of the mean for the data point. 
the resulting broccoli to midsummer in the northeastern United States as well.

Results of the South Carolina and New York field trials clearly illustrate that not all broccoli hybrids will perform the same in nonconventional, high-temperature environments. Although previous researchers (Grevsen, 1998; Wurr et al., 1995) have modeled broccoli growth and development in relation to temperature, it is clear that some of the models (based on only one or two genotypes) may describe only certain individuals. For example, the hybrids that failed to head in the South Carolina trials fall into a class of hybrids that probably require a vernalization triggered by temperatures below $23{ }^{\circ} \mathrm{C}$ like those described by Wurr et al. (1995). This group of individuals likely encompasses many commercial hybrids (many patterned after the industry standard 'Marathon') that are primarily adapted to arid, western environments for which cool night temperatures are typical.

'Packman' and 'Gypsy' fall into a separate class of hybrids that exhibit arrested inflorescence development at higher temperatures as described by Björkman and Pearson (1998), resulting in poor-quality heads with flaws such as irregular shape, uneven bead size, and off color. These varieties do not require vernalization but they do require lower temperatures for development of high-quality heads.

The experimental USVL hybrids that are single crosses of inbreds selected for adaptation to southeastern summer conditions represent a unique class of broccoli genotypes that do not require cool temperatures for development of inflorescences or high-quality heads. Considering the similar performance of these hybrids in the very different fall and summer environments in South Carolina and across summer transplanting dates in New York, it would appear that head development in these individuals is unaffected by temperature ranges observed in South Carolina and New York. It is also important to note that all of the experimental hybrids have relatively early maturity. This earliness did not allow these individuals to escape heat, but they do advance more quickly to the stage of head formation.

Development of heat-tolerant broccoli has been a goal of many public and commercial breeding programs for more than 20 years. Success on the commercial front is difficult to assess because formal trials evaluating relatively new culitvars have not been published. Information on public efforts to develop heat tolerant broccoli is also limited. Dr. M. Dickson (Cornell University) informally released broccoli germplasm in the early 1990s that he deemed heat-tolerant, but no formal descriptions of these materials were ever published. The Ching-Long Seed Company was the first to formally describe a "heat-tolerant" broccoli hybrid (Yang et al., 1998). This hybrid was adapted to Asian conditions where temperatures range from 30 to $35^{\circ} \mathrm{C}$ during the day and 25 to $30^{\circ} \mathrm{C}$ at night. Two patents related to "heat-tolerant broccoli" were filed in 1999 and 2001 by Barham and Joynt (2001, 2004); the first patent claimed "heat-tolerant" inbred lines and the second patent claimed rights to the trait of "heat tolerance" as exhibited by lines described in the first patent. Heat-tolerant germplasm described in the two patents was developed and tested in California environments that were characterized by relatively high day temperatures and night temperatures much lower than $23{ }^{\circ} \mathrm{C}$ (Barham and Joynt, 2001, 2004).

The experimental USVL summer-adapted hybrids were derived from materials that would be deemed non-conventional by modern broccoli standards. Original sources for these hybrids include the old broccoli hybrids 'Green Comet' and 'Paragon' that likely originated from Asian programs and the germplasm developed by M. Dickson at Cornell (Table 1). The original sources of these materials are now difficult to obtain. When the USVL program was initiated in the early 1990 s, inbred lines were selected from the three original heterozygous sources and then recombined to make novel combinations of alleles. Current hybrids such as USVL HY5 combine factors from these three sources and represent several rounds of recombination. Based on pedigrees by Barham and Joynt (2001, 2004), they developed heat-tolerant broccoli from very different sources than those used to develop the experimental USVL hybrids.

Results of this research indicate that the response of broccoli hybrids to summer conditions of the eastern United States is dependent on the specific genotype grown. Many hybrids are not adapted to such conditions because they will not be vernalized as the season warms and will therefore not head. We expect that many commercial broccoli hybrids that have been selected for adaptation to western U.S. climates will respond in this manner. Of those that do head, the nonuniform arrest of bud development results in a rough-appearing curd in which flower buds are at various stages of development. Observations from field trials described here indicate that broccoli hybrids bred for adaptation to southeastern summers are not damaged by the high day and night temperatures that are typical of these environments. Limited testing of these experimental USVL hybrids in summer trials in New York indicate that they may have wider adaptation to other summer conditions. Further widescale testing must be accomplished to determine just how wide this adaptation will extend.

\section{Literature Cited}

Barham, R. and D. Joynt. 2001. Heat tolerant broccoli. United States Patent No. 6,294,715. Granted 25 Sept. 2001.

Barham, R. and D. Joynt. 2004. Heat tolerant broccoli. United States Patent No. 6,784345. Granted 31 Aug. 2004.

Björkman, T. and K.J. Pearson. 1998. High temperature arrest of inflorescence development in broccoli (Brassica oleracea var. italica L.). J. Expt. Bot. 49:101-106.

Boodley, J.W. and R.J. Sheldrake. 1977. Cornell peat-lite mixes for commercial plant growing. Cornell Information Bulletin Number 43.

Dufault, R.J. and M.W. Farnham. 1996. Broccoli varieties for spring, summer and fall in coastal South Carolina. 1995-96 Clemson University Vegetable Report, p. 11-12.

Farnham, M.W., M.A. Grusak, and M. Wang. 2000. Calcium and magnesium concentration of inbred and hybrid broccoli heads. J. Amer. Soc. Hort. Sci. 125:344-349.

Fontes, M.R. and J.L. Ozbun. 1972. Relationship between carbohydrate level and floral initiation in broccoli. J. Amer. Soc. Hort. Sci. 97:346-348.

Fontes, M.R., J.L. Ozbun, and S. Sadik. 1967. Influence of temperature on initiation of floral primordial in green sprouting broccoli. J. Amer. Soc. Hort. Sci. 91:315-320.

Gauss, J.F. and G.A. Taylor. 1969. Environmental factors influencing reproductive differentiation and the subsequent formation of the inflorescence of Brassica oleracea L. var. italica, Plenck, cv. 'Coastal'. J. Amer. Soc. Hort. Sci. 94:275-280.

Grevsen, K. 1998. Effects of temperature on head growth of broccoli (Brassica oleracea L. var. italica): Parameter estimates for a predictive model. J. Hort. Sci. Biotechnol. 73:235-244.

Heather, D.W., J.B. Sieczka, M.H. Dickson, and D.W. Wolfe. 1992. Heat tolerance and holding ability in broccoli. J. Amer. Soc. Hort. Sci. 117:887-892.

Miller, C.H., T.R. Konsler, and W.J. Lamont. 1985. Cold stress influence on premature flowering of broccoli. HortScience 20:193-195.

U.S. Department of Agriculture, Economic Research Service. 2010. Vegetables and melons yearbook data; Table 2. 6 Dec. 2010. <http://usda.mannlib. cornell.edu/MannUsda/viewDocumentInfo.do? documentID $=1212>$.

Warne, L.G.G. 1961. Juvenile stage in cultivated forms of Brassica oleracea. Nature 192:889.

Wurr, D.C.E., J.R. Fellows, K. Phelps, and R.J. Reader. 1995. Vernalization in calabrese (Brassica oleracea var. italica) - A model for apex development. J. Expt. Bot. 46:1487-1496.

Yang, Y.W., C.C. Tsai, and T.T. Wang. 1998. A heat-tolerant broccoli F1 hybrid, 'Ching-Long 45’. HortScience 33:1090-1091. 